\section{JUAN LARREA EN MÉXICO: EL FIN ANUNCIADO DEL YO SUBJETIVO EN DIARIO DEL NUEVO MUNDO}

\author{
Katrine Helene Andersen \\ University of Copenhagen \\ ORCID iD: https://orcid.org/0000-0002-6481-2804 \\ Kandersen@hum.ku.dk
}

Cómo citar este artículo/Citation: Andersen, K. H. (2020). Juan Larrea en México: el fin anunciado del yo subjetivo en Diario del Nuevo Mundo. Arbor, 196 (797): a566. https://doi.org/10.3989/ arbor.2020.797n3003

Recibido: 23 agosto 2019. aceptado: 16 diciembre 2019.

RESUMEN: El presente artículo demuestra que el anhelo por el más allá que había expresado Juan Larrea en su poesía llega a su culminación en Diario del Nuevo Mundo. La experiencia vivida en el exilio mexicano le impulsa a abandonar el yo subjetivo y dejarse absorber por una conciencia objetiva que viene a constituir el epicentro de su proyecto filosófico. De esta manera, Larrea funda en Diario del Nuevo Mundo los principios constitutivos de una filosofía transcendental a la vez que describe la situación personal en la que se encuentra. Además, el artículo mantiene que Larrea es de los más radicales entre los pensadores exiliados en su crítica de la racionalidad tecno-científica y que el proyecto de Larrea solo es posible porque se apoya en disciplinas tradicionalmente marginalizadas dentro de la filosofía como son la psicología, la religión y la poesía.

PALABRAS CLAVE: Juan Larrea; Diario del Nuevo Mundo; exilio republicano; pensamiento español.

\section{JUAN LARREA IN MEXICO: THE ANNOUNCED END OF THE SUBJECTIVE SELF IN DIARIO DEL NUEVO MUNDO}

Copyright: (C) 2020 CSIC. Este es un artículo de acceso abierto distribuido bajo los términos de la licencia de uso y distribución Creative Commons Reconocimiento 4.0 Internacional (CC BY 4.0).

ABSTRACT: This article shows that the longing for the great beyond, already expressed by Juan Larrea in his poetry, culminates in Diario del Nuevo Mundo. While exiled in Mexico, he abandons the subjective self and is absorbed by an objective consciousness that will later become central to his philosophical project. This is how Juan Larrea sets down in Diario del Nuevo Mundo the fundamental principles of a transcendental philosophy while, at the same time, describing his personal situation. In addition, the article asserts that Larrea was the most radical amongst the contemporary exiled thinkers in his critique of the techno-scientific reason and that his philosophical project is feasible only because he relies on disciplines traditionally marginalized within philosophy such as psychology, religion and poetry.

KEYWORDS: Juan Larrea; Diario del Nuevo Mundo; republican exile; Spanish philosophy. 


\section{INTRODUCCIÓN}

Aproximadamente medio año después de su llegada a México en 1939 junto con el resto del grupo de republicanos españoles acogidos por el México de Cárdenas, Juan Larrea (1895-1980) escribe la primera entrada en su diario de la época. Durante poco menos que siete años y medio va rellenando folios, con mayor o menor constancia, todos los cuales se publicarían casi 70 años después bajo el título Diario del Nuevo Mundo. Es un manuscrito genéricamente muy diverso, que descubre su situación personal, al tiempo que van cobrando forma algunas de las ideas claves en la filosofía del bilbaíno. La obra abarca un período esencial en la vida del poeta y, además de las observaciones subjetivas e ideas sueltas que presenta, supone el testimonio directo del proceso de desintegración del yo que viene a catalizar en él tras desembarcar en el "Nuevo Mundo" el que, como se arguye en lo siguiente, va a ser fundamental para su filosofía posterior.

La poesía de Juan Larrea había estado marcada por un fuerte anhelo del más allá; en el Diario, se percibe claramente el mismo anhelo, pero aquí le provoca la disolución del yo subjetivo para penetrar en una realidad transcendente y colectiva. En el presente estudio voy a demostrar cómo Larrea abandona el yo subjetivo (o cómo el yo subjetivo abandona a Larrea) y cómo su deseo de dejarse absorber por un Ser universal y transcendental expresado en su poesía se efectúa en el Diario. Salta del sujeto concreto a lo abstracto como base epistemológica para poder acceder al más allá, de modo que la universalidad transcendental se convierte en el epicentro de su pensamiento.

No es posible llegar a las conclusiones a las que arriba Larrea apoyándose en la racionalidad filosófica tradicional, sino que hace falta toda una red de disciplinas y metodologías. Aunque bien es cierto que el pensamiento larreano es muy singular y personal, sin precedentes ni parecidos, en lo siguiente las ideas de Heidegger, Freud y James van a servir como marco conceptual para demostrar las varias fuentes y disciplinas que convergen en él. Además, demostraré que Larrea era de los más radicales entre los exiliados españoles en su intento de renovar la tradición filosófica española y europea y el que más ferozmente se oponía al pensamiento lógico-especulativo y racional. Como reitera Antolín Sánchez Cuervo, el pensamiento exiliado, a pesar de su heterogeneidad, tiene en común una crítica de occidente y un afán por renovar los modos del pensar filosófico (Sánchez Cuervo, 2008). Del pensamiento exiliado emana un humanismo que considera que la condición humana sea irreductible a los criterios de la racionalidad tecno-científica (Sánchez Cuervo, 2015, p. 182). Sánchez Cuervo no incluye a Larrea en su estudio, pero el bilbaíno se suma, sin duda, a este humanismo y lo lleva incluso más lejos, como veremos en lo siguiente.

\section{UNA NUEVA FILOSOFÍA TRANSCENDENTAL NACIDA EN EL “NUEVO MUNDO”}

Juan Larrea es de las voces más sonoras en el coro de exiliados en México que defendía la existencia de unos valores espirituales que unían a los españoles con el "Nuevo Mundo" y que identificaba el exilio americano con una universalidad. Sebastian Faber propone que los republicanos españoles subscribían a una idea histórica de hispanismo, hispanoamericanismo o panhispanismo al insistir en la relación histórica y espiritual entre España y América Latina (Faber, 2002b, pp. 130-135), pero la de Larrea es una idea más radical y universal ya que no solo defiende la relación entre la España republicana y América sino entre el viejo continente y el "Nuevo Mundo". Según Larrea, el "Nuevo Mundo" brinda la posibilidad de alcanzar una cultura universal, además de una experiencia personal que afecta su relación con lo colectivo y lo transcendental de la que deja constancia en el Diario del Nuevo Mundo. Larrea no da una definición exacta de su idea del más allá o del Ser-espíritu, como también lo llama, entre muchas otras denominaciones. Pues no le interesa la definición sino la relación entre el sujeto individual y un ente objetivo transcendental, pero el lector intuye que se trata de un ser transcendental y universal de carácter espiritual e incluso religioso. A veces habla de una Voluntad objetiva, otras veces de una Conciencia objetiva o de un Ser-espíritu además de un Amor de América porque esa universalidad se articula principalmente en el "Nuevo Mundo".

A primera vista, la obra de Larrea se divide en dos períodos cronológica y genéricamente separados: la poesía de su juventud se sustituye en la madurez por el ensayo. No obstante, existe una clara continuidad entre las dos etapas, ya que la poesía como fuerza filosófica tiñe toda su obra (Abellán, 1983, p. 194). La crítica se ha centrado casi exclusivamente en el análisis de los versos de la primera etapa, y son casi inexistentes los estudios dedicados a sus ensayos y a sus obras publicadas fuera de Europa. Durante los últimos años, sin embargo, ha empezado a reeditarse y redescubrirse la obra del bilbaíno, y el interés intelectual por este poeta-filósofo exiliado va en aumento ${ }^{1}$. La reciente publicación del Diario 
del Nuevo Mundo es resultado de esta tendencia. Comienza en abril de 1940 y concluye en agosto de 1947. Aunque no sean constantes las entradas -en 1946 no se produce o no se conserva ninguna-, abarcan un período crucial en su pensamiento, así como en su vida personal. En estos años se acuñan las ideas centrales de su prosa y la poesía empieza a ocupar una posición más teórica y abstracta tras el abandono del verso. Uno de los temas centrales de las anotaciones que constituyen el Diario es la Voluntad o Conciencia objetiva (que habitualmente escribe con mayúscula), es decir, lo transcendente y colectivo. A primera vista, resulta paradójico caracterizar de diario unas páginas dedicadas a lo universal, pero un estudio detenido demuestra que no se trata, en efecto, de un diario íntimo al estilo unamuniano, sino de un manuscrito que describe la situación y la experiencia vivida en el "Nuevo Mundo". Ricardo Tejada incluye en su estudio del ensayo en el exilio republicano el diario como género ensayístico, y matiza que "el diario puede convertirse en un cuaderno de bitácora del exilio [...] [E]s un verdadero laboratorio de ideas y de esbozos conceptuales y sensoriales" (Tejada, 2010, p. 222). Tejada opina que no debemos entender el exilio como una categoría sino como una experiencia que deja su impronta en la escritura de todos los exiliados por mucho tiempo. Igual que a muchos de los exiliados contemporáneos, la experiencia del exilio le marcó profundamente a Larrea. Como cofundador de la Junta de cultura española estuvo en contacto con muchos de los intelectuales españoles exiliados de la época como León Felipe, Eugenio Ímaz, José Bergamín, para mencionar solamente a algunos. Además, su círculo de amigos contaba con figuras importantes de la poesía como Gerardo Diego, Vicente Huidobro y César Vallejo con los que había trabado amistad durante su estancia en París en los años veinte (Bary, 1984; Díaz de Guereñu y Bernal Salgado, 2017). Intelectualmente se encuentra entre varias tradiciones y disciplinas y geográficamente se mueve entre Bilbao, Madrid, París, Perú, México, Estados Unidos y finalmente Argentina. Tal vez por estas circunstancias vitales, también su pensamiento es difícil de categorizar. No obstante, en el caso de Larrea, la experiencia del exilio no se plasma en su diario como una melancolía o frustración por la nacionalidad perdida, sino que entiende su situación con optimismo, como una nueva oportunidad que llevaba años anunciándose y que le permite elaborar una filosofía que le aleja de las metodologías y tradiciones europeas corrientes. Pues la suya es una filosofía que incorpora la poesía, la religión y la psicología en un pensamiento multidisciplinar que tiene como objetivo llegar a una idea de lo universal. Paradójicamente, las experiencias personales vienen a ser claves en este proceso, como vemos a continuación.

Su primer encuentro físico con el "Nuevo Mundo" se produce en los años 1929-31 cuando pasa dos años en Perú, pero también su amistad con César Vallejo le despierta una fuerte conexión con el "Nuevo Mundo"2. La estancia en Perú deja su clara impronta en el poeta y la consecuencia más concreta es el abandono del verso. Estando en el país andino declara el fin de su poesía y anuncia en el diario de la época, Orbe, que va a hacer de su vida un proyecto poético dejando libre entrada en su vida real a todos los componentes de la poesía como son la imaginación, el sentimiento y la armonía (Larrea, 1945/1990, pp. 29-30). En Diario del Nuevo Mundo alude en varias ocasiones a las experiencias vividas en Perú; allí le operan de una úlcera duodenal y durante su convalecencia "nació la conciencia optimista en reacción contra la insuficiente situación individual, afirmándose así sobre los valores particulares los propios de la generalidad" (Larrea, 2015, pp. 89-90). En el prólogo a la edición italiana de Versión Celeste de 1969, asegura que su producción intelectual "derivó hacia otros rumbos no menos poéticos en realidad, aunque sí más objetiva y concretamente culturales" (Nieto, 2003, p. 61). Es decir que cuando escribe el manuscrito que va a constituir el Diario del Nuevo Mundo ha dejado de escribir poesía y ha empezado a ocuparse de asuntos culturales, filosóficos y teóricos en los que la universalidad y el más allá son temas primordiales, pero la poesía sigue muy vinculada a su modo de pensar.

Al ubicar la poesía en el auge de su filosofía, Larrea aleja su pensamiento de la tradición filosófica europea y en especial del uso de la razón. En Razón de ser, va a mantener que la filosofía europea aspira a racionalizar aquello que no corresponde con la comprensión de la razón y la lógica para dar cabida a lo transcendental en la conciencia humana, pero esta noción de las limitaciones de la conciencia humana empieza ya a plasmarse en el Diario. En algunos sentidos sus reproches a la filosofía europea contemporánea se hacen eco de la crítica de Martín Heidegger a la filosofía científica y comparte con los filósofos contemporáneos españoles un escepticismo hacia el uso instrumental de la razón. En momentos en los que la tendencia dominante de la filosofía europea era hacer 
de la filosofía una ciencia, filósofos como Zambrano, Gaos y Xirau daban la espalda a una tradición filosófica que pretendía hacer de la razón una entidad estática garante de conocimiento y de la filosofía una disciplina científica (Sánchez Cuervo, 2008). No obstante, resulta más esclarecedor como punto de comparación con Larrea el caso de Martin Heidegger, quien pretende volver sobre las cuestiones primordiales de la metafísica y plantea la pregunta fundamental: ¿qué es metafísica? ya que, aunque Juan Larrea no dibuja una metafísica per se, existe en su pensamiento una preocupación por la relación entre el ser existente y el ser-espiritual y transcendental que apunta a una metafísica. Para Heidegger el objetivo fundamental de la metafísica es la pregunta por el Ser o la Nada, que están intrínsecamente vinculados. La filosofía es la puesta en marcha de la metafísica, mientras que las ciencias que se aferran al ente sin atreverse a abandonarse a la Nada se tornan ridículas (Heidegger, 1967, pp. 108-111). En el caso de Larrea, la clave también está en abandonar el ente para dejarse absorber por la totalidad y pensar al margen de los ideales científicos. Es decir, ya eran perceptibles en Europa las tendencias filosóficas que cuestionaban el ideal científico de la filosofía que imposibilitaba una metafísica, y ya se habían comenzado a producir los primeros intentos de transformar la tradición filosófica basada en la razón y la lógica, pues la reflexión del exilio del 39 acerca de las particularidades del "pensar español" discurre de la mano de una conciencia de crisis de la racionalidad filosófica (Sánchez Cuervo, 2009, p. 131). La conciencia amorosa de Joaquín Xirau y la razón poética de María Zambrano son dos excelentes ejemplos de la respuesta hispana a esta crisis, pero la reacción a la crisis filosófica e histórica de Larrea es más radical. No aspira a definir una tradición filosófica especialmente española sino universal, aunque reconoce que España y los españoles desempeñan un papel privilegiado en la búsqueda de lo universal debido a su relación histórica con el "Nuevo Mundo" ya que geográficamente el fin del viejo continente (Finisterre) se sitúa en la Península Ibérica e históricamente los españoles fueron los primeros del viejo continente en pisar el "Nuevo Mundo" (Larrea, 1943). El "Nuevo Mundo" es donde se hace posible la definitiva ruptura con las tradiciones científicas y racionales del viejo continente y la fundación de una nueva vía dentro de la filosofía. Este proceso se manifiesta como una experiencia personal en Larrea tras la llegada a América.

La poesía está presente en el manuscrito como la reminiscencia de un género abandonado y como una visión del mundo. Larrea suscribe a la idea de Heide- gger que defiende que "[I]a poesía no es un adorno que acompaña la existencia humana [...] La poesía es el fundamento que soporta la historia" (Heidegger, 2006, p. 104). El bilbaíno comprende la realidad y la historia como poéticas. Desarrolla la idea de la realidad poética en sus contribuciones a la revista España Peregrina donde hace una lectura poética de la historia y pretende mostrar una relación espiritual y cultural entre España y América Latina históricamente fundada más allá de la colonización (Faber, 2002b, p. 132). Larrea halaga a Heidegger por recurrir a la poesía en busca del Ser (Larrea, 1974, pp. 171-172), pero opina que su Dasein cae en la misma trampa que todos los existencialismos: toman al hombre como punto de partida de su filosofía y pretenden dar cabida al Ser en la conciencia humana (Larrea, 1974, p. 28). Así se crea una filosofía a la medida del hombre que nunca se sale del ámbito psicosomático. Larrea considera que ni la razón ni la conciencia individual del yo le proporcionan las herramientas necesarias para alcanzar aquello que busca. En un principio, los dos se aproximan a la cuestión de la metafísica desde perspectivas distintas a pesar de considerar ambos que la metafísica requiere una nueva metodología o vía de acceso: la de Heidegger es una vía que deduce y razona para llegar a una comparación entre el Ser y la Nada (Heidegger, 1967), mientras que Larrea pretende abandonar la lógica y basar su filosofía en facultades tradicionalmente marginalizadas en la filosofía, para lo cual integra en su aparato filosófico la religión, la poesía, la ciencia ${ }^{3}$ y la imaginación. Es más, en el Diario elimina el yo para filosofar desde la Conciencia objetiva, porque solo así es posible dar cabida al Ser. Una filosofía metafísica y transcendental solo es posible si el punto de partida es la conciencia objetiva y no la subjetiva. En este sentido, no acepta la idea cartesiana del sujeto pensante como punto de partida para una verdad universal. Las meditaciones de Descartes no pueden ser metafísicas porque parten del sujeto y de la conciencia somática, diría Larrea.

La argumentación de Larrea está llena de inconsistencias y paradojas, pero su resultado final es un repensar radical de la manera tradicional de hacer filosofía. La posterior denominación de su proyecto filosófico como un pensar "poético-cultural" (Abellán, 1998, p. 317) suscribe, por un lado, a la idea del mundo como un problema hermenéutico representado en España desde el Barroco (Blumenberg, 2000) y, por otro lado, Larrea propone que el verdadero problema no es el mundo, sino el yo individual como sujeto pensante que lo interpreta. 


\section{LA RELACIÓN ENTRE LA VIDA EXTERIOR E INTERIOR}

Ya durante su producción de poemas Larrea empieza a centrarse en el espíritu objetivo y a abandonar la idea de un sujeto o un yo individual como centro de la identidad. Juan Manuel Díaz de Guereñu (1995, p. 18) propone que Larrea deja el verso tras descubrir el sentido de la historia y la vida y su visión poética de la realidad. En el Diario da cuenta de la transición por la que ha pasado y del papel que desempeña la poesía en su obra. La poesía no es un género literario sino una dimensión de la realidad que engloba la totalidad además de posibilitar el pasar de una conciencia a otra:

En lo individual histórico percibo la congruencia precisa que se observa entre las regiones conscientes a las que tan inopinadamente, más bien en calidad de náufrago, he arribado y mi posición inicial, profundamente poética, comprendida la poesía como potencia de creación. Esa actitud inicial encerraba, en forma de semilla, la capacidad de tránsito de un mundo a otro mundo, de una conciencia a otra conciencia (Larrea, 2015, p. 161).

Diario del Nuevo Mundo presenta el tránsito de un mundo a otro y describe la relación entre el yo subjetivo y las dimensiones transcendentales y absolutas de la realidad. El lector es testigo de un proceso de desintegración del yo que ocurre gradualmente y que ya había comenzado años atrás.

El manuscrito comienza con una clara intención de pasar página tanto en lo personal como en lo general: "[d]esde anoche estoy cambiado interiormente", pero también "[l]a tragedia española ha vencido su fase aguda. Lugar existe, pues, para que en el nuevo clima otros brotes se abran paso" (Larrea, 2015, p. 35); el "Nuevo Mundo" constituye el escenario idóneo para el cambio y el florecimiento de una voluntad suprema por encima del yo individual. Los conceptos de cultura y espíritu que constituían la columna vertebral en el grupo de exiliados en México (Faber 2002a; Faber, 2002b) se interiorizan en el Diario de Larrea y se convierten en un asunto personal a la vez que transcendental. Larrea entiende, por un lado, la importancia de su herencia cultural española y la relación con América Latina, pero al mismo tiempo rompe con la tradición filosófica anterior aniquilada por la razón. La ruptura con la vida anterior no es solo un cambio geográfico y de género literario, sino que supone la culminación definitiva de la historia anterior y connota universalidad: “América [...] La universalidad se concibe aquí, se acrisola aquí. Todo concurre, material y espiritualmente" (Larrea, 2015, p. 47). Concurre su vida personal con el plano general; pues todo, desde los puntos que recibe su mujer - Guite- en una operación quirúrgica y que al serle quitados connotan un nuevo comienzo, y la pérdida de su reloj, un regalo de su madre que murió el mismo día en que Larrea llegó a América, apuntan a una nueva conciencia y una nueva percepción de la vida. La muerte de la madre y la pérdida del reloj vienen a simbolizar una ruptura con los viejos tiempos y el inicio del "tiempo del hijo" (Larrea, 2015, pp. 52-53). No obstante, pese a simbolizar el "Nuevo Mundo" el comienzo de una nueva era, no rompe del todo con el mundo antiguo. Se vuelven a presentar tiempos anteriores, siendo en forma de la reaparición de la pluma estilográfica con la que solía escribir (Larrea, 2015, p. 61) o en forma de viejos amigos que se trasladan al nuevo continente y con ellos "los antiguos tiempos a este continente" (Larrea, 2015, p. 62), de modo que se trata de la culminación de la historia y no de su fin. Desde el primer momento el autor relaciona lo físico y corporal con los cambios. Lo físico le hace comprender que la existencia se rige por una voluntad superior. La vida en este mundo, el cuerpo y el yo individual son impotentes e insignificantes frente a esa voluntad, al tiempo que participan de ella. Ya en Orbe había presentado esta idea; Carlos Peinado Elliot habla de una voluntad inconsciente de la que el hombre es el mero efecto (Peinado Elliot, 2013, p. 11) y asegura que Larrea pretende negar la voluntad individual para concordarla con la voluntad primordial (Peinado Elliot, 2013, p. 28). El hombre ha dejado de ser un fin en sí mismo (Peinado Elliot, 2013, p. 26) y se puede añadir que el centro del pensamiento larreano es una visión cosmológica y una humanidad universal del que el yo individual forma parte. No obstante, los acontecimientos físicos y algo tan carnal como las enfermedades físicas le proporcionan, en repetidas ocasiones, un cambio de conciencia y le acercan al ser y a la voluntad superior. Así, por ejemplo, describe la recuperación de su hijo tras una enfermedad grave como "horas angustiosísimas" durante las que experimenta "la no existencia práctica del yo" (Larrea, 2015, p. 49). En la misma situación en la que vive algo tan concreto y subjetivo como la enfermedad de un hijo, el yo deja de tener existencia práctica y voluntad personal, y es absorbido por una voluntad objetiva superior. La paradoja es obvia, pero no hace más que subrayar el modus del pensamiento de Larrea. Cada suceso tiene un significado por encima del actual y entra en una dia- 
léctica o "dinamismo", como lo llamaría Larrea, con un ser superior y universal que le concede un significado superior; así pues, concibe la recuperación de su hijo como un renacimiento simbólico que representa la resurrección de todo el mundo occidental. Juan Jaime es la personificación del hombre nuevo, "del más allá humano" (Larrea, 2015, p. 50). Es hijo de madre judía y padre católico, y esta unión judeocristiana simboliza la resurrección del mundo en el "Nuevo Mundo".

La relación entre lo físico, lo mental y lo geográfico se establece en Lima donde tuvo "por primera vez conciencia de la relación íntima entre enfermedad física y salud mental" y esta idea promueve en él el afán por buscar las conexiones entre psiquismo y fisiología. Apunta Larrea:

Todas mis enfermedades se han hallado como subordinadas a la conciencia, hasta el punto de que llegado el momento en que salta la chispa de la comprensión la enfermedad cede si no desaparece (Larrea, 2015, p. 110).

La enfermedad física obedece a una conciencia superior y colectiva caracterizada por ser optimista. Abre paso a avances en otros campos, de modo que, al sufrir un trastorno importante es preciso salir en busca de su sentido "abrir los ojos, disponerse a comprender" (Larrea, 2015, p. 111). El éxodo de los exiliados lleva a un definitivo despertar en el orden del "Nuevo Mundo" que, para Larrea, es el orden de "Amor de América". No es un orden impuesto por un ser superior en el sentido religioso sino un orden al que contribuyen todos los seres humanos y que, por eso, es común y universal. El sujeto en sí mismo carece de valor, pero la voluntad objetiva se manifiesta a través del sujeto, de modo que la siente como algo personal. La voluntad optimista no proviene del yo "sino de la esencia vital a través de la entidad Nuevo Mundo" (Larrea, 2015, p. 91), es independiente del ego y deriva de un conjunto de realidades que se sitúan más allá de la personalidad y del yo (Larrea, 2015, p. 92). El yo y la voluntad no son idénticos. Antes había dado por hecho que el yo poseía una voluntad y que negar el yo sería negar la voluntad, pero ahora comprende que la voluntad es colectiva por mucho que su vía sea el sujeto. Existe una voluntad dinámica que puede operar "en diversos campos como son el histórico de las grandes fuerzas creadoras, en el inconsciente y fortuito, en el consciente y voluntario lo mismo del individuo que de la colectividad" (Larrea, 2015, p. 84). Esta voluntad es universal y colectiva y se refiere a ella por medio de las siguientes expresiones: voluntad objetiva, volun- tad activa, conciencia objetiva, voluntad de conciencia y AMOR DE AMÉRICA (en mayúsculas). Larrea no es consistente en su denominación del fenómeno, pero se trata de un ser colectivo y universal que une en sí a todos los hombres y que se consolida y acrisola en el "Nuevo Mundo". Se revela de manera objetiva, pero Larrea también lo siente en su interior, a pesar de todo él es sujeto de sensaciones, pero gradualmente empieza a sentir la síntesis entre los mundos objetivo y subjetivo (Larrea, 2015, p. 130). ${ }^{4}$

\section{DEL YO CONCRETO AL SER ABSOLUTO POR LA VÍA PSICOLÓGICA Y LA EXPERIENCIA RELIGIOSA}

Tras haber llegado a la voluntad y conciencia universal concluye con cierta dificultad que el yo teóricamente no existe; el 8 de noviembre de 1943 no percibe prescindir del yo, pero al día siguiente le parece que la solución está en "el otro". Cuenta:

[...] he estado viviendo la no existencia absoluta del "yo", lo que supone la existencia absoluta del "otro". Estaba como durmiendo, con el dinamismo apoyado en el no-yo. No había por consiguiente movimiento en "mí". Sin embargo, la situación de síntesis supone el dinamismo total, incluso a través de un "yo" relativo, a sabiendas de su no existencia absoluta. La voluntad, discriminada del "yo", debe influir también sobre el individuo, animando su personalidad relativa, su núcleo dinámico (Larrea, 2015, p. 93).

La no-existencia absoluta del yo le roba el fundamento, pero se apoya en el "otro" que le asegura una relación con el ser superior que sí tiene una existencia absoluta. Resalta "el otro" y abandona el yo porque ya no tiene validez en sí. A partir de este momento, se centra en el nuevo mundo y ya no le concierne su yo personal. Ha sido un despertar a un nuevo mundo en el que rige una conciencia colectiva y optimista, es un "[a]brir los ojos a esa voluntad que no es mi voluntad, sino la voluntad universal" (Larrea, 2015, p. 98). El 19 de noviembre de 1943 sepulta definitivamente el yo subjetivo y concluye que "yo soy Él" (Larrea, 2015, p. 103). Siente claramente la existencia de un yo, sujeto de sus sensaciones, pero ese yo solo existe gracias a "Él". Él es el Ser absoluto cuya existencia está por encima de todo y el yo existe como una mera representación relativa de Él:

Soy yo, puesto que la sensación de ser, imprescindible para la vida, ha de identificarse con Él, de manera que puede decirse que, teórica, mentalmente, yo no existo, mas sensiblemente, según la sensación subjetiva, yo soy Él (Larrea, 2015, p. 103). 
Según Miguel Nieto Nuño, la transformación o desintegración del yo ya había empezado a producirse en la obra poética de Larrea. Divide su poesía en dos etapas: la primera "agónicamente modernista" y la segunda "vanguardista". Ese cambio no solo es el resultado de una nueva estrategia retórica, sino que obedece a una exigencia estética más radical. En la primera etapa la transcendencia es una proyección especular de la identidad y la subjetividad creadora permanece como punto reflexivo, mientras que, en la segunda etapa -la que se corresponde con el poema "Evasión" y el poemario Versión Celeste-, el poema posee menor carga de subjetividad y se percibe un espíritu poético objetivo (Nieto Nuño, 1995, p. 10). Robert Gurney, por su parte, señala que el "yo" en la poesía se vuelve un "se" y subraya que el fin de la producción poética de Larrea pudo deberse a la ruptura definitiva con el estado de extrema subjetividad (Gurney, 1985, p. 308). La poesía de Larrea presenta a menudo un "tú" femenino o una "ella" a la que dirige muchos de sus poemas. Gurney propone que sea la personificación de la luz espiritual o la vida y constituye el móvil metafísico central de la poesía larreana. "Ella" es una proyección del propio espíritu del poeta y representa el anhelo de una conciencia personal de sentido (Gurney, 1985, pp. 287-288). Destaca una tendencia en Versión Celeste a buscar la conciencia de la luz a través de un descenso en el yo (Gurney, 1985, p. 289) aunque también subraya los aspectos místicos y religiosos en la poesía del bilbaíno que le permite aspirar al más allá. Como hemos visto, en el Diario el "tú" o "ella" se reemplaza por "Él" y el yo llega a identificarse con Él tras un largo proceso de disolución del yo como subjetividad. El primer paso es el diagnóstico del cuerpo como insuficiente y el siguiente es enfrentar el yo individual a un ser superior y metafísico. La idea cristiana del dolor como camino hacia el progreso espiritual resuena aquí, pero Larrea tira de los avances en el campo de la psicología para justificar el contacto entre la realidad corporal y la realidad superior y metafísica.

Toma prestada la idea freudiana del psiquismo defendido por una censura que lo protege de todo aquello que ponga en peligro la realidad aparencial y conocida. Larrea mantiene que el hombre concibe a Dios como una proyección o abstracción que existe en un plano independiente, de modo que no puede manifestarse de manera directa en este mundo (Larrea, 2015, p. 44). Se hace eco de Freud al proponer que lo psíquicamente reprimido se manifies- ta indirectamente por infiltración en, por ejemplo, sueños y produce, de esa suerte, imágenes y figuras. En Tótem y tabú, Freud reitera que el sueño, por muy inconexo y absurdo que parezca en un primer instante, proporciona material para nuestro conocimiento. Existe una función intelectual en nosotros que requiere la unificación y comprensión de todo lo que pensamos y percibimos de modo que construye conexiones entre todo, aunque estas no concuerdan con la realidad. Así elabora significados a partir de los sueños y los incorpora en nuestra comprensión del mundo (Freud, 1946, pp. 123-124). Freud resalta el estado de paranoia que esta relación de significados puede ocasionar, mientras que Larrea se queda con la idea para establecer una conexión entre el individuo y lo universal y para explicar una posible manifestación o revelación del segundo ante el primero. Mantiene que elementos colectivos y "antiindividuales" se infiltran en el sueño de la conciencia. Solo se manifiestan directamente figuras individuales y por eso lo universal se disfraza de individuo y así se dan a conocer figuras individuales como Adán y Cristo (Larrea, 2015, p. 44). Es probable que Larrea haya leído Tótem y tabú, que se tradujo al español en el 1923, aunque no hace mención directa de la obra sino de su autor. No obstante, su uso de las ideas freudianas no tiene por objetivo llegar a una mayor comprensión del psiquismo individual o de una definición del subconsciente, sino que se apoya en el psicólogo austriaco para subrayar que a través de la modificación de la conciencia en el individuo se modifica su relación con el plano sobrenatural y hace posible que "[I]a psique se funde en el alma colectiva" (Larrea, 2015, p. 45). Resulta paradójica la presencia de Freud dentro de un discurso impregnado de religiosidad, pero en varias ocasiones Larrea se apoya en marcos conceptuales establecidos de diversas disciplinas como la psicología, la mística, la poesía y la filosofía para alcanzar su meta; Larrea busca una síntesis entre el sujeto y la realidad colectiva (Morelli, 2015, p. 10), aunque en ocasiones duda de la existencia de un sujeto independiente y para ello le sirven las ideas de Freud. Freud explica que tradicionalmente se ha considerado que existen tres sistemas de pensamiento fundamentales: el animista (mitológico), el religioso y el científico. El primero explica el mundo en su totalidad; es el más exhausto y constituye la base sobre la que surgía posteriormente la religión y finalmente el sistema científico. Representan la evolución de la comprensión humana del universo (Freud, 1946, pp. 114-115), es decir que el sistema más primitivo es el primero. Hoy en 
día, aspectos del sistema animista se reflejan en los estados de psicosis y en los neuróticos (Freud, 1946, p. 101). El Ilamado "pensar omnipotente", es decir la sobreestimación de los procesos psíquicos sobre la realidad, era frecuente en los pueblos primitivos, pero también lo es en los neuróticos. Durante el estado animista el ser humano atribuía la omnipotencia a sí mismo, en el estado religioso se la concedía a los dioses sin renunciarla del todo ya que el ser humano ejercía influencia sobre los dioses a través de sus deseos, mientras que en el sistema científico no entra la idea de omnipotencia del pensar porque el ser humano se ha rendido frente al sistema y a la muerte (Freud, 1946, p. 115). La idea del pensar omnipotente constituye un punto clave en Larrea. En el caso del bilbaíno no es síntoma de una anomalía psíquica, sino un imprescindible en la relación entre el yo individual y el Ser-espíritu (el más allá). Se aleja de una comprensión científica de la mente humana porque esta se centra en la actividad cerebral e imposibilita todo contacto directo con un ser superior y transcendental y, en cambio, se alía con pasadas visiones del mundo para comprender la realidad tal y como las explica Freud.

Aparte de las alusiones a la psicología, la filosofía de la Larrea también tiene una clara inspiración religiosa. La enfermedad relacionada con el renacimiento, así como la muerte, la resurrección y el amor vienen a ser términos sobre los que construye su pensamiento. En otro lugar he estudiado el carácter místico de las experiencias vividas en la sierra andina tal y como el autor da constancia de ellas en Orbe (Andersen, 2018), pero también algunas de las experiencias testimoniadas en Diario del Nuevo Mundo poseen rasgos místicos. Las experiencias religiosas permiten, según William James, lograr la unión con algo que está por encima de nosotros y en esa unión reside nuestra mayor paz (James, 2015, p. 751). Incluir las experiencias religiosas en el campo de la filosofía y la epistemología le ha ganado a James mucha crítica, pero arguye que las experiencias religiosas conceden a la comprensión del mundo un componente personal y de simpatía del que carece la comprensión puramente científica (Larrea, 2015, pp. 699-700). Larrea le daría la razón; pues la suya es un proyecto filosófico que necesita del amor y la imaginación. El gran problema para Larrea es que la ciencia no consigue establecer un vínculo entre el individuo y el poder transcendental y para ello le sirven la psicología, las experiencias religiosas y, como hemos visto, su concepto de la poesía. La manera de pensar de Larrea se aleja de la especulación pura y se aproxima a la relevación. Él es sujeto sensorial de las ideas, pero aparecen en él como resultado de la Voluntad y la Conciencia objetiva. Muchas de sus experiencias son claramente místicas según los criterios de James (James, 2015, pp. 537-613) y Larrea siente la unión con un ser superior a nivel personal, por ejemplo:

\section{Despertar.}

Abrir los ojos a esa voluntad que no es mi voluntad, sino la voluntad universal.

Conciencia.

[...]

Abrir los ojos a esa voluntad significa tener la mira puesta en el destino de América, en su amor y en la imaginación creadora que le presta una dimensión propia, universal, un orden nuevo. Es integrarse en el dinamismo absoluto, tanto como en el objetivo en el subjetivo.

Todo es, una vez más, para lo mejor (Larrea, 2015, p. 98).

Él mismo inserta la experiencia en su proyecto filosófico y la deja apuntar al más allá, pero no llega a su conclusión por medio de la especulación lógica, sino que acepta la irracionalidad de la experiencia. Los criterios que James enlista para una experiencia mística: inefabilidad, calidad noética, transitoriedad y pasividad (James, 2015, pp. 538-540) podrían bien caracterizar la experiencia que precede al "despertar" aquí descrito. Larrea no la describe en detalle, pero intuimos claramente que algo le ha empujado hacia esa nueva integración en "el dinamismo absoluto", algo parecido a una experiencia religiosa.

\section{CONCLUSIÓN}

La crisis europea, la derrota de la Segunda República española y las guerras no solo simbolizan un fin, sino un comienzo que, para Juan Larrea, se produce en el "Nuevo Mundo" porque allí se articula la universalidad que venía anunciándose históricamente. Ya en las publicaciones integradas en las revistas España Peregrina y Cuadernos Americanos, de las que Larrea fue cofundador y contribuyente incansable, el acento se traslada de la individualidad y la nacionalidad a la universalidad (Larrea, 1940; Larrea, 1942). Asimismo, el libro Rendición de Espíritu de 1943, basado principalmente en las contribuciones a las primeras ediciones de España Peregrina, pero publicado en su conjunto durante los años del Dia- 
rio, es una lectura cabal y profética de destacados acontecimientos históricos en la que, entre otras cosas, demuestra la relación inherente entre el viejo y el nuevo mundo (Faber, 2002b, p. 130). En el Diario interpreta los acontecimientos personales del pasado como una premonición de lo que viene a producirse después de modo que el Diario constituye el complemento personal de Rendición de Espíritu y de sus publicaciones contemporáneas en Cuadernos. Larrea asume que ha resucitado en el "Nuevo Mundo" con un elevado nivel de conciencia que le ha hecho comprender que su existencia personal no es relevante, sino que la existencia de la Voluntad o Conciencia objetiva es el centro de la realidad y de la vida. Se da cuenta de que este proceso de concienciación lleva años produciéndose. Explica que "[e] xiste un pensamiento objetivo, una voluntad objetiva a la cual se encuentra mi fenómeno individual adscrito. Ambos han trabajado a través de mi subjetividad en acorde con los sucesos exteriores" (Larrea, 2015, p. 120). Comprende que forma parte de algo superior, de un colectivo universal, y no solo su voluntad sino sus pensamientos se adscriben a una objetividad universal. Si durante la escritura de Orbe y de su poesía se debatía en una crisis personal porque buscaba escapar de sí mismo y transcender este mundo (López González de Orduña, 2001; Díaz de Guereñu, 1990), aquí se da cuenta de que el salto no puede producirse individualmente. Su yo individual es sujeto de sensaciones y como tal un ser tangible, de modo que no puede saltar de lo concreto a lo abstracto. Pero al deshacerse del cuerpo como sede de la identidad personal y poner énfasis en la parte notangible del yo, que entra en la relación dialéctica con el otro, y así crear el dinamismo que caracteriza el ser, le es posible transcender este mundo y alcanzar el más allá. Describe la situación como "una situación de síntesis en que los mundos objetivo y subjetivo confluyen y concuerdan" (Larrea, 2015, p. 126) y gradualmente se disuelve el yo personal. El mismo yo que al principio carecía de existencia práctica va dejando su voluntad en manos de una conciencia objetiva. Lo subjetivo se convierte en objetivo y el yo se convierte en Él (Larrea, 2015, p. 103) como resultado de un proceso que describe como "dinamismo". El yo existe como preámbulo para poner de relieve la existencia del otro. Solo porque existen los dos opuestos se crea el dinamismo y la síntesis. El modelo evoca la dialéctica de Hegel, en quien Larrea se inspira muy a menudo, pero sin subscribir del todo su modelo. A pesar de la clara inspiración hegeliana, Larrea critica en Razón de ser a Hegel porque trata el Espíritu desde una perspectiva racional; a pesar de ser el Espíritu racional en su expresión, es "supra-racional" en su esencia y consecuentemente no contenible por la razón (Larrea, 1974, p. 146). Según Larrea, Hegel comete el error de la mayoría de los filósofos europeos; pues recurren a la razón en su intento de explicar el mundo, pero, objeta Larrea, ni el Espíritu ni aquello que une la humanidad es racional.

En algunos sentidos, Larrea subscribe la crítica a la filosofía hispana lanzada por Eduardo Nicol quien considera que "la soberanía del yo" ha anclado el pensamiento español en un personalismo en el que incluso las relaciones más formales se convierten en personales (Nicol, 1998, p. 164). Ambos pretenden huir de un individualismo excesivo que imposibilita la metafísica, aunque llegan a su objetivo por vías muy distintas. Otro de los filósofos exiliados, José Gaos, propone que Larrea, especialmente en Rendición de Espíritu, inserta el cabalismo y el gnosticismo en el auge de la filosofía (Gaos, 1945, p. 348), pero para Larrea se trata de un proyecto filosófico poético que, como he demostrado aquí, tira de otras disciplinas tradicionalmente ajenas a la filosofía como la poesía, la psicología y la religión para poder cumplir con su propósito: Ilegar al más allá y al ser transcendental.

En definitiva, Larrea pretende crear un proyecto filosófico que dé cabida al más allá y al Ser-espíritu, cosa que la filosofía contemporánea europea y española no han logrado; para ello tiene que deshacerse del yo subjetivo y dejar que el proyecto se desarroIle desde la Conciencia colectiva y tiene que alejarse de la razón como vehículo filosófico. El resultado es un proyecto filosófico multidisciplinar que José Luis Abellán ha calificado de "pensamiento delirante" (Abellán, 1998, p. 285), y el mismo Larrea reconoce que su pensamiento se diferencia de la lógica académica (Abellán, 1998, pp. 317-318). Asegura que sus convicciones son producto no de una conciencia racional sino de una "revelación" (Abellán, 1998, p. 319). Es como si otro revelara o pensara algo en él. El Diario nos demuestra que este "otro" es la Conciencia colectiva y que solo porque se deshace de la racionalidad tecno-científica y tira de otras disciplinas humanísticas le es posible dar cuenta del proceso por el que pasa. 


\section{NOTAS}

1. De los últimos años destacan: la antología de Gabriele Morelli Poesía y Revelación de 2009 , la primera desde la que realizó Cristóbal Serra en 1979; La religión del lenguaje español de 2013, obra prologada por Juan Manuel Díaz de Guereñu, la biografía de José Fernández de la Sota de 2014, así como El Diario del Nuevo Mundo de 2015 y Del surrealismo a Machupicchu de 2019.

2. Juan Larrea dedica sus últimas publicaciones a la obra de César Vallejo, pero ya en el prólogo a España, aparta de mi este cáliz, Larrea identifica a Vallejo con una profecía de América que se anunciaba en Europa: “César Vallejo [...] es un emisario de América cuya misión ha consistido en dar [...] testimonio de Nuevo Mundo, cualificando con su pre-

\section{BIBLIOGRAFÍA}

Abellán, J. L. (1983). De la guerra civil al exilio republicano (1936-1977). Madrid: Mezquita.

Abellán, J. L. (1998). El exilio filosófico en América. Los transterrados de 1939. Madrid: Fondo de Cultura Económica.

Andersen, K. H. (2018). Juan Larrea y el Nuevo Mundo: entre la filosofía y la mística. Annales Universitatis Marie Curie-Sklodowska, Sectio I, PhilosophiaSociología, 43 (2), pp. 9-25. https://doi. org/10.17951/i.2018.43.2.9-25

Bary, D. (1984). Nuevos estudios sobre Huidobro y Larrea. Valencia: Pre-Textos.

Blumenberg, H. (2000). La legibilidad del mundo. Barcelona: Paidós.

Díaz de Guereñu, J. M. (1990). Orbe de Juan Larrea. Ínsula. Revista de Letras y Ciencias Humanas, 527, pp. 7-8.

Díaz de Guereñu, J. M. (1995). Versión Celeste, Cabeza de Puente. Ínsula. Revista de Letras y Ciencias Humanas, 586, pp. 18-20.

Díaz de Guereñu, J. M. y Bernal Salgado, J. L. (eds.) (2017). Introducción. Gerardo Diego Juan Larrea. Epistolario. 1916-1980. Madrid: Fundación Gerardo Diego / Residencia de estudiantes, pp. XV-XLV.

Dunne, J. W. (1958). An experiment with time. London: Faber and Faber.

Faber, S. (2002a). Contradictions of leftwing hispanismo: The case of the Spa- sencia la significación de los acontecimientos que se desarrollan en España" (Vallejo, 1961, p. 16).

3. Candelas Gala estudia las reminiscencias científicas en Orbe y en Versión Celeste. A pesar de su escepticismo hacia la comprensión racional del mundo, Larrea siente una profunda atracción por la física moderna, en especial por la teoría de la relatividad y la cuarta dimensión (Gala, 2011, pp. 73-97).

4. La Conciencia universal deja ver el dinamismo del Ser y con él las relaciones complejas que existen entre las cosas, por ejemplo, entre pasado y futuro. Larrea lee a William Dunne quien en Una experiencia con el tiempo propone que los sueños habilitan una relación

nish Republicans in exile. Journal of Spanish Cultural Studies, 3 (2), pp.165-185. https://doi.org/10.1080/14636200220 00013965

Faber, S. (2002b). Exile and cultural hegemony. Spanish intellectuals in Mexico, 1939-1975. Nashville: Vanderbilt University Press.

Fernández de la Sota, J. (2014). Juan Larrea (El hombre al que perseguían las palomas). Bilbao: El Gallo de Oro.

Freud, S. (1946). Totem and taboo. New York: Random House.

Gala, C. (2011). Poetry, Physics, and Painting in Twentieth-Century Spain. New York: Palgrave Macmillian. https://doi. org/10.1057/9781137002181

Gaos, J. (1945). Pensamiento en lengua española. México: Stylo.

Gurney, R. (1985). La poesía de Juan Larrea. Bilbao: Servicio Editorial Universidad del País Vasco.

Heidegger, M. (1967). ¿Qué es Metafísica? Buenos Aires: Siglo XX.

Heidegger, M. (2006). Arte y poesía. México: Fondo de Cultura Económica.

James, W. (2015). The Varieties of Religious Experience. New York: Philosophical Library/Open Road.

Larrea, J. (1940). Introducción a un nuevo mundo. España Peregrina, 1, pp. 21-26. profética con el futuro porque mezclan en igual medida experiencias pasadas con experiencias futuras (Dunne, 1958, pp. 59-73). Larrea relaciona la idea de Dunne con la imaginación y arguye que Colón y los conquistadores han estado motivados por la imaginación; pues se imaginaron el "Nuevo Mundo"; por eso podría decirse que sus sueños "obedecían en parte a la realidad futura" (Larrea, 2015, p. 131). Es la misma idea que le posibilita a Larrea hacer una lectura profética de la historia como la que hace en Rendición de Espíritu donde interpreta la historia en función del porvenir, es decir, aquello a lo que apunta, en vez de una lectura causal que comprende la historia retrospectivamente

Larrea, J. (1942). Nuestra alba de oro. Cuadernos Americanos, 1, pp. 51-72.

Larrea, J. (1943). Rendición de espíritu (introducción a un mundo nuevo). México: Cuadernos Americanos.

Larrea, J. (1974). Razón de ser. Tras el enigma central de la cultura. Madrid: Ediciones Júcar.

Larrea, J. (1945/1990). Orbe. Barcelona: Seix Barral.

Larrea, J. (2015). Diario Del Nuevo Mundo. Madrid: Fundación Banco de Santander.

Larrea, J. (1967/2019). Del surrealismo a Machupicchu. Madrid: Instituto Cervantes.

López González de Orduña, H. (2001). Hacia una definición de Orbe de Juan Larrea. Bulletin of Hispanic Studies, LXXVIII (3), pp. 361-370. https://doi. org/10.1080/000749001300342070

Morelli, G. (ed.) (2009) Juan Larrea. Poesía y revelación. Madrid: Fundación Banco de Santander.

Morelli, G. (2015). Nace un nuevo ser. En: Morelli, G. (ed.) Juan Larrea. Diario del Nuevo Mundo. Madrid: Fundación Banco de Santander, pp. 9-22.

Nicol, E. (1998). El problema de la filosofía hispánica. México: Fondo de Cultura Económica.

Nieto, M. (ed.) (2003). Juan Larrea. Versión Celeste. Madrid: Cátedra. 
Nieto Nuño, M. (1995). La escritura automática en Larrea. Ínsula. Revista de Letras y Ciencias Humanas, 586, pp. 10-12.

Peinado Elliot, C. (2013). Inconsciente y voluntad en los textos inéditos de Orbe (1926-1931), de Juan Larrea. Nueva Revista de Filología Hispánica, 61 (1), pp. 147-179. https://doi.org/10.24201/ nrfh.v61i1.1127

Sánchez Cuervo, A. (2008). Pensar a la intemperie. El exilio de la filosofía y la crí- tica de occidente. En: Sánchez Cuervo, A. (ed.). Las huellas del exilio. Madrid: Tébar, pp. 57-93.

Sánchez Cuervo, A. (2009). El exilio del 39 y su contribución a la reflexión sobre la filosofía en lengua española. Revista de Hispanismo Filosófico, 14, pp. 129-139.

Sánchez Cuervo, A. (2015). El exilio en América Latina: itinerarios del pensamiento. En: Santana, A y Velázquez, A. (coords.). Docencia y cultura en el exilio republicano español. México:
Universidad Nacional Autónoma de México, pp. 179-190.

Tejada, R. (2010). El ensayo: ventana sin par del exilio republicano español. En: Sánchez Cuervo, A. y Hermida de Blas, F. (coords.). Pensamiento exiliado español. El legado filosófico del 39 y su dimensión iberoamericana. Madrid: Biblioteca Nueva / Consejo Superior de Investigaciones Científicas, pp. 203-229.

Vallejo, C. (1961). España, aparta de mí este cáliz. Lima: Perú Nuevo. 